\title{
EDITORIAL
}

\section{Electroacoustic musics: a century of innovation involving sound and technology - resources, discourse, analytical tools}

On 15-17 October 2003, a three-day conference took place at the Pompidou Centre in Paris forming part of IRCAM's annual Résonances event. 'Electroacoustic Musics' was inspired by the EARS project (ElectroAcoustic Resource Site, MTI Research Group, De Montfort University) and initiated by the MTI and the MINT group of the Universite de Paris - Sorbonne. This conference was designed to bring together reflections concerning the better understanding of electroacoustic music and to make relevant initiatives more widely available - from this music's genesis, its appearance and its development spanning a century. Its premise was that most gatherings in the field focused primarily either on the music, the technology or both, yet few focus on the developments these musics represent as well as the impact that new technologies have had on both music-making and appreciation. The scientific steering committee of the October 2003 conference also included representation from IRCAM, the Groupe de Recherches Musicales (GRM), the Electronic Music Foundation (EMF) and the Musée de la Musique (Paris).

Five years ago, one of us, Leigh Landy, published a plea in Organised Sound suggesting that the musicological study of electroacoustic music (in the broadest, most inclusive sense) was under-represented (Landy 1999). Furthermore, it suggested that new frameworks should be put in place to further the understanding of the music and aid in the coherence of what today might be called electroacoustic music studies. Much has happened since this time, and yet that article's basic premise still rings true to a large extent. Those foundations have yet to be created; most scholarly research seems to exist within small sub-areas of development.

It was thus decided to create a biannual event, of which this was its launch, focusing on various areas within electroacoustic music studies (electroacoustics in Canada), reaching an international audience. Its core committee at the time of writing this Editorial consists of three members: the MINT group, the MTI Research Group and the GRM. The first edition of the event focused on three areas; the following themes were proposed in our announcement:

\section{SOURCES AND RESOURCES}

- What types of materials are being or should be documented?

- How does one create, expand, preserve and offer access to collections?

- Which opportunities exist for exchange and collaboration?

- How can we help make the electroacoustic repertoire more accessible?

This subject concerned the methods for the construction, preservation and dissemination of documentation and deserves a few words of introduction. Trying to answer these questions, many of which were addressed during the conference, only raises further problems. And yet, how can electroacoustic music studies become a fertile field if steps are not taken to ensure that researchers will find all the necessary material? In this process, several types of institutions have a role to play: museums, for one, increasingly acquire twentieth-century electric instruments and electronic musical devices. Electronic music studios, research and creation centres ought to feel pressure for researchers to keep and preserve composition materials for study. Libraries and archives, also, while not present during the conference, have a substantial role to play in preserving recordings, scores and miscelleanous printed matter. Also, because electroacoustic music is used in so many venues and genres, art and film museums, concert organisations and documentation centres, finding means of access to sources must also be considered. Finally, access to private composers' personal archives forms part of this large landscape of source materials.

\section{DISCOURSE/ANALYSIS OF ELECTROACOUSTIC WORKS}

- What types of discourse are relevant to electroacoustic works?

- Which forms of representation and which approaches to analysis are useful?

- Which methods are particularly important?

- How does one adapt existent analytical methods of music to electroacoustic works, many of which involve no prescriptive notation? 
- How does one study the role of digital systems, of computer scripts (e.g. patches, virtual instruments, scores, event lists) and of performance (e.g. use of gestural controls, interpretation, diffusion)?

- Which types of representation are pertinent to the various approaches to analysis?

- Generally, how does one arrive at a point where musicologists become more engaged with these repertoires (including today's varieties of electroacoustic music)?

This second theme is perhaps the more humanitiesbased theme of the three. It has been represented more often in Organised Sound thus far than the other two themes and therefore probably needs no further introduction.

\section{ANALYTICAL TOOLS $=$ CREATIVE TOOLS?}

- How have such analytical tools for these repertoires been produced and made accessible to others?

- What are the means of linkage between the world of sounds and those of the score and other forms of representation?

- Are these tools specific to the genre, however loosely this term might be used, or can they be applied to any type of music?

- To which extent does the study of electroacoustic musics require specific tools?

An additional day, which was shared with the simultaneous conference on Set Theory, included a major focus on research at the host institution, IRCAM. The day ended with a round table that featured researchers from this institution. Leaning on practical techniques currently in use and in development, this day raised several questions concerning the routes to be taken for the study of electroacoustic musics and composition processes associated with computer-based composition.
The reaction to our call for contributions was beyond all expectations, attracting contributors from all continents with the exception of Africa. Perhaps things were not so bad after all. The spread of subjects was broad, yet the points of intersection were quite evident even as the first day progressed.

What is published here is a selection of the contributions from last October. These have been chosen both to be of interest to the readership of Organised Sound and to suggest the breadth of the subject areas involved. Articles by Fujii, Teruggi, Atkinson/Landy, Battier and Ramel all concern the resources theme from very different viewpoints. Discourse/analysis was not surprisingly the theme with the greatest number of submissions. We have included texts by Chadabe, Young, Mountain, Tanzi and Zattra in this issue related to this theme. Finally, articles by Bossis, Donin and Couprie reflect the theme of analytical tools.

We would like to thank colleagues at IRCAM as well as the Pompidou Centre for hosting this event and offering translation assistance. This was the first of what is intended to become a series of conferences that will take place every other year under the auspices of the newly founded Electroacoustic Music Studies Network. A call for the 2005 event, which is to take place in Montreal, should be circulating by the time this issue has appeared. As this event falls very much within the scope of Organised Sound, selected papers from future events will continue to be published in the journal.

Marc Battier Leigh Landy

\section{REFERENCE}

Landy, L. 1999. Reviewing the musicology of electroacoustic music. Organised Sound 4(1): 61-70. 